\title{
Cognitive Translation Studies: Models and methods at the cutting edge
}

\author{
Kairong Xiao \\ College of International Studies, Southwest University \\ kairongxiao@163.com \\ https://orcid.org/0000-0002-6967-3268 \\ Ricardo Muñoz Martín \\ MC2 Lab, Università di Bologna \\ ricardo.munoz@unibo.it \\ https://orcid.org/0000-0001-6049-9673
}

\begin{abstract}
Several indicators seem to suggest that, through nearly six decades of development, Cognitive Translation Studies (CTS) may be taking shape as an autonomous field of study. The main challenges ahead seem to be building sounder theoretical models and carrying out more rigorous methodological scrutiny. These two strands converge as central themes in the 11 contributions to this special issue of LANS-TTS. To provide a context for theoretical modelling and to frame critical discussions of the methods included in this volume, we first trace the present landscape of CTS and how it evolved so as to test Holmes' criteria for disciplines: founding new channels of communication and sharing a "disciplinary utopia". The contributions are arranged into four thematic categories as applied to CTS, namely, scientometrics, framing or reframing our field, the reliability and validity of popular research methods, and new methods or novel approaches. This article closes with a call to reflect on some fundamental issues on the next steps of humankind regarding communication, with evergrowing societal demands and expectations that call for refreshing our notions of translation in the context of increasingly diversified forms of multilectal mediated communication.
\end{abstract}

Key words: Cognitive Translation Studies (CTS); Cognitive Translation and Interpreting Studies (CTIS); models; methodology; criticism; reliability; validity

\section{Introduction}

Since the 1960s, shortly after the inception of cognitive science, the interest in studying what happens in the minds of translators and interpreters started to take shape gradually. That initial interest developed into what we now call Cognitive Translation Studies (CTS), a research realm devoted to studying the cognitive aspects of communicative production, reception and interaction of all participants in events where more than one language variety or lect is used (Halverson \& Muñoz, 2020; Muñoz \& Martín, 2020). We could have also used the term Cognitive Translation \& Interpreting Studies (CTIS) because these labels are often meant to be exact synonyms. Defenders of CTS argue that there are many more tasks that are not 
Xiao, K. \& Muñoz, R. (2020). Cognitive Translation Studies: Models and methods at the cutting edge. Linguistica Antverpiensia, New Series: Themes in Translation Studies, 19, 1-24

explicitly present in the term but also covered - for example, post-editing, subtitling, transcreation and audio description - and that, in the term CTS, translation is used as a hypernym. Proponents of CTIS hold that interpreting research has an older and clearer cognitive tradition, well anchored in the social sciences, that interpreting includes most or all oral and signed tasks, and that many (written) translation researchers often forget their professed comprehensiveness and focus on written-only aspects and phenomena. Both sides are right. We prefer CTS over CTIS, simply for economy, as we did in the title of this issue of Linguistica Antverpiensia, New Series: Themes in Translation Studies, but from now on in this text we shall use CTIS to underscore our strong commitment to oral, written and signed language integration in CTIS and also to remind readers that our civilization is becoming more and more oral, thanks to audiovisual communications.

According to Olalla-Soler et al. (this volume), the earliest CTIS publication was an article on the psychology of translation published in 1910. They have also documented some publications in the 1950s and the 1960s, a notable growth in the 1970s and the 1980s, and a considerably larger increase since 1996. That is, they suggest that CTIS toddled its first steps between the 1960s and the 1980s, followed by a rapid growth and entrenchment since the mid-1990s. The bottom line might be that the steps forward have been both steady and steadily bigger. Furthermore, there is very little overlap with the topics studied in other areas of Translation Studies (TS) - even when the label is shared, as in the case of reception - and scarce are the cross-citations between CTIS and the rest of TS. CTIS has proved, indeed, to be quite autonomous within TS. Should we then consider CTIS as a discipline apart from TS?

In his article on the name and nature of TS, Holmes (1972/2000) laid out his vision of a discipline that would open the linguistic status quo of the previously unnamed TS to a wider humanistic tradition and defined two standards by which to judge the legitimacy of a discipline to become or consider itself autonomous: establishing new channels of communication and developing a new disciplinary utopia, that is, "a shared interest in a common set of problems, approaches, and objectives on the part of a new grouping of researchers" (p. 172). Let us consider how CTIS has fared in the light of these two standards.

\section{Channels of communication}

In terms of communication channels, it is not an overstatement to declare that CTIS has boomed. Muñoz (2014) already considered it a boom when he listed 11 CTIS books in the seven years between 2006 and 2013. In the following seven years, edited books with independent chapters by different authors include at least: 
Xiao, K. \& Muñoz, R. (2020). Cognitive Translation Studies: Models and methods at the cutting edge. Linguistica Antverpiensia, New Series: Themes in Translation Studies, 19, 1-24

\begin{tabular}{|c|c|c|c|}
\hline 1 & 2014 & The development of translation competence & Schwieter \& Ferreira \\
\hline 2 & 2015 & $\begin{array}{l}\text { Psycholinguistic and cognitive inquiries into translation and } \\
\text { interpreting }\end{array}$ & Ferreira \& Schwieter \\
\hline 3 & 2016 & New directions in empirical translation process research & Carl, Bangalore \& Schaeffer \\
\hline 4 & & $\begin{array}{l}\text { Describing cognitive processes in translation: Acts and } \\
\text { events }\end{array}$ & Ehrensberger-Dow et al. \\
\hline 5 & & Re-embedding translation process research & Muñoz \\
\hline 6 & 2017 & Empirical modelling of translation and interpreting & Hansen-Schirra, Czulo \& Hofmann \\
\hline 7 & & $\begin{array}{l}\text { Translation in transition: Between cognition, computing and } \\
\text { technology }\end{array}$ & Jakobsen \& Mesa \\
\hline 8 & & The handbook of translation and cognition & Schwieter \& Ferreira \\
\hline 9 & 2018 & Innovation and expansion in Translation Process Research & Lacruz \& Jääskeläinen \\
\hline 10 & & Eye tracking and multidisciplinary studies of translation & Walker \& Federici \\
\hline 11 & 2019 & Researching cognitive processes of translation & Li, Lei \& He \\
\hline 12 & 2020 & The Routledge handbook of translation and cognition & Alves \& Jakobsen \\
\hline 13 & & Multilingual mediated communication and cognition & Muñoz \& Halverson \\
\hline
\end{tabular}

In addition to edited volumes, publications in scientific periodicals may be added as indicators of a research field's maturity. CTIS seems to have been a welcome topic for TS journals because there have been least ten special or thematic issues published on CTIS and even specific topics within CTIS in this period, including: ${ }^{1}$

\begin{tabular}{|c|c|c|c|}
\hline 1 & 2014 & Minding translation & Monti Special issue 1 \\
\hline 2 & & The development of professional competence & Translation \& Interpreting Studies 9:1 \\
\hline 3 & 2015 & Translation as a cognitive activity & Translation Spaces 4:1 \\
\hline 4 & & Translation Process Research & Translation \& Interpreting 7:1 \\
\hline 5 & 2016 & Cognitive space: Exploring the situational interface & Translation Spaces 5:1 \\
\hline 6 & & Language processing in translation & $\begin{array}{l}\text { Poznan Studies in Contemporary } \\
\text { Linguistics 52:2 }\end{array}$ \\
\hline 7 & 2017 & Translation practice in the field & Translation Spaces 6:1 \\
\hline 8 & 2018 & Expertise and behaviour & Hermes 57 \\
\hline 9 & 2019 & Cognitive explorations of translation and interpreting & Perspectives 27:4 \\
\hline 10 & 2020 & CTS: Theoretical models and methodological criticism & LANS-TTS 19 \\
\hline 11 & & Developments of CTIS & Cognitive Linguistic Studies 8:2 \\
\hline
\end{tabular}

There have also appeared a few monographies, including, at least:

\footnotetext{
${ }^{1}$ The editors of these special issues are (1) Muñoz; (2) Ehrensberger-Dow, Englund Dimitrova, \& Hubscher-Davidson; (3) Alves, Hurtado, \& Lacruz; (4) Giozza, Jääskeläinen, Mellinger, \& RodríguezInés; (5) Ehrensberger-Dow, \& Englund Dimitrova; (6) Whyatt; (7) Risku, Rogl, \& Milošević; (8) Klimant, Tieber, \& Risku; (9) García, \& Giozza; (10) Muñoz, \& Xiao; (11) Xiao, \& Halverson.
} 
Xiao, K. \& Muñoz, R. (2020). Cognitive Translation Studies: Models and methods at the cutting edge. Linguistica Antverpiensia, New Series: Themes in Translation Studies, 19, 1-24

\begin{tabular}{|c|c|c|c|}
\hline 1 & 2014 & Translation and web searching & Enríquez \\
\hline 2 & 2017 & Translation and emotion. A psychological perspective & Hubscher-Davidson \\
\hline 3 & & Researching translation competence by PACTE group & Hurtado \\
\hline 4 & 2019 & $\begin{array}{l}\text { Eye movements and gestures in simultaneous and consecutive } \\
\text { interpreting }\end{array}$ & Stachowiak-Szymczak \\
\hline 5 & & The neurocognition of translation and interpreting & García \\
\hline 6 & 2020 & An eye-tracking study of equivalent effect in translation & Walker \\
\hline 7 & & A relevance-theoretic approach to decision-making in subtitling & Bogucki \\
\hline 8 & & Eye-tracking processes and styles in sight translation & $\mathrm{Su}$ \\
\hline 9 & & Problem-solving activities in post-editing and translation from scratch & Nitzke \\
\hline 10 & & $\begin{array}{l}\text { Translation and affect: Essays on sticky affects and translational } \\
\text { affective labour }\end{array}$ & Koskinen \\
\hline
\end{tabular}

We cannot be exhaustive - and not only because publications in languages other than English are more difficult to trace. For instance, there may be as many contributions in generic anthologies and journals (i.e., not exclusively on CTIS). Be that as it may, from what we have been able to locate, since 2014 there have been more than 300 articles or chapters, an average of more than 40 per year - a $50 \%$ increase when compared to the previous seven years! If we include relevant research in Machine Translation (MT) and Natural Language Processing, bilingualism, and neuroscience, we are probably reaching the psychological landmark of one paper per week. This is impressive but, essentially, not new.

Nevertheless, an international network - Translation · Research $\cdot$ Empiricism $\cdot$ Cognition (TREC) - has since 2010 linked a prominent set of CTIS researchers, who now have many opportunities to meet regularly and present their works in several conference series, including, since 2014, the CSTIC-initiated annual International Conference on Cognitive Research on Translation and Interpreting (ICCRTI); and, since 2017, TREC's biennial International Conference on Translation, Interpreting and Cognition (ICTIC). Furthermore, in 2018, a new journal was started devoted to CTIS, Translation, Cognition \& Behavior, which is publishing two issues per year. Another journal has just been launched in Chongqing: 语言、译与认知 (Studies in Language, Translation \& Cognition). This is all new. In sum, CTIS meets and probably excels as a new discipline according to the criterion of new channels of communication.

\section{In search of a new disciplinary utopia}

In terms of Holmes' "disciplinary utopia", CTIS researchers generally share the overall objective of studying cognition in multilectal mediated tasks. As the central goal of CTIS is to "model the cognitive processes of translation" (Risku, 2014, p. 334), researchers have attempted to build models to depict aspects of translational cognition, based mostly on the concepts and theoretical frameworks borrowed from neighboring disciplines such as psychology, neuroscience, and linguistics, or from some sub-disciplines such as writing, reading and language technology ( $\mathrm{O}^{\prime}$ Brien, 2013). In fact, interdisciplinary inspiration is an outstanding feature of model building in CTIS. 
Xiao, K. \& Muñoz, R. (2020). Cognitive Translation Studies: Models and methods at the cutting edge. Linguistica Antverpiensia, New Series: Themes in Translation Studies, 19, 1-24

Over approximately six decades, we have come a long and tangled way. There are several takes on our evolution through the years, some dividing it into three or four stages. We will add to these views by offering yet another account in five stages, conscious as we are that none of these accounts can on its own fully explain the rich and complex conceptual development of our thriving research realm. Our story starts when a bunch of scholars, mainly linguists, takes up the challenge handed out to them by the ALPAC report explaining how human beings translate (Muñoz, 2016a).

In the first period, between the mid-1960s and the mid-1980s - before the foundation of TS - we witnessed the first attempts to develop theoretical models for cognition in translation and interpreting. In Europe, the most prominent schools were the Science of Translation, by scholars in the Forschungskollektiv Übersetzungswissenschaft of the University of Leipzig, and the Interpretive Theory of Translation, by scholars at today's Paris University of Sorbonne Nouvelle. Several international conferences were held in Leipzig between 1965 and 1986, but probably the meeting that was more representative of the times was held in Venice in 1977 (Gerver \& Sinaiko, 1978).

With a strong influence by Chomskyan generative linguistics, the Leipzig scholars aimed at developing translation grammars, with a focus on setting up the transfer rules for switching language codes (Muñoz \& Martín, 2020). They proscribed the study of literary translation but tried to make their account valid for both translation and interpreting. In 1964, Otto Kade (1968), a conference interpreter, defended the first-ever PhD dissertation on translation. They soon realized that (generative) linguistics could not provide all the answers. As Eugene Nida (1964) had done before, Jäger (1975) suggested that correspondence between text stretches need not necessarily be formal, that the notion of equivalence (that they had inherited from the early stages of MT) might not be sufficient or adequate to account for what people do.

Meanwhile, in 1968 Danica Seleskovitch published her first book on interpreting. She later worked together with Lederer to develop their approach as a challenge to the prevailing view that translation was no more than a linguistic activity. Basing their work on introspection and on the observation of (mainly simultaneous) interpreting, they focused on interpreters rather than on texts - and developed a three-step model of interpreting (and, later, translation); this model consisted of comprehension, reformulation and production. The intermediate stage happened in the black box, and they hypothesized that in the black box meaning became deverbalized.

In our view, the Leipzig and the Paris schools, as they came to be known, were similar in that they both were deductive and rationalistic, and they crucially differed in that Leipzig focused on translating and drew from linguistics, whereas Paris centered on interpreters and borrowed mainly from psychology. They both fell equally short in delivering sound progress, and this paved the way for widening the realm to include the rest of the approaches in departments of languages, literatures and cultures, our new hosts. We also think, however, that they made huge and positive steps to foster and shape CTIS. We are enormously indebted 
Xiao, K. \& Muñoz, R. (2020). Cognitive Translation Studies: Models and methods at the cutting edge. Linguistica Antverpiensia, New Series: Themes in Translation Studies, 19, 1-24

to researchers such as Delisle, Harris, Kade, Komissarov, Levý, Ludskanov, Neubert and Wotjak, and all the members of that first generation who blazed today's trodden trails.

The second period of CTIS started in the mid-1980s, when we witnessed a distinction that would prevail in the following decades. Probably inspired by precedent splits between basic versus theoretical research in MT (the first based on trial-and-error learning; the second addressing fundamental overarching questions from a more philosophical perspective) and between applied and "hyphenated" linguistics versus theoretical linguistics in generativism, CTIS - then still without a name - would split into two lines: one more empirically driven, the other more theoretical, as if they could survive separately from each other.

On the one hand, a group of (written) translation researchers crossed the front lines and adopted psychology - actually, psycholinguistics - as a referential framework. Following Sandrock (1982), this avant-garde borrowed Think-Aloud Protocols (Ericsson \& Simon, 1980) as a data-collection method and presented their works at an International Symposium on Discourse and Cognition in Translation and Second Language Acquisition held at the University of Hamburg in August 1984 (House \& Blum-Kulka, 1986). Most researchers in this line implicitly, and sometimes acritically, adopted the prevailing information-processing views as they centered on empirical testing. The foundations, therefore, remained unscathed, while these researchers often focused on translators' problem-solving ways.

On the other hand, from the beginning to the mid-1990s several cognitive models of translation popped up, such as Neubert's (1994) and Wilss' (1996), pointing to a need to articulate our own, "internal" vision of the field, as Seleskovitch (1968) had argued before. These models were inherently inspired by one or more neighboring disciplines, mostly based on information-processing views, largely conceptual, and seemingly distant from empirical support or refutation. For instance, drawing on constructs and notions from psycholinguistics and artificial intelligence (Al, or natural language processing), Bell (1991) mixed generative notions - such as successive syntactic, semantic, and pragmatic processing - with British linguistics and psychological constructs such as short-term and long-term memory (p. 44) to develop a translation process model comprising two steps: analysis and synthesis (p. 46).

Gutt (1991) was more successful with his coherent Chomskyan views. He developed a model of translation based on Sperber and Wilson's (1986) relevance theory of language use (that drew, in turn, from Fodor's views on language and meaning). Gutt (1991) also adopted a classical, information-processing view: he was concerned with competence as a mental faculty, not with real behavior, and thought of the mind as modular. He also suggested that context is a set of premises; that thoughts are mental representations in propositional form; that meaning can be quantified and computed in terms of the sum of implicatures and explicatures; and that translators must understand texts in terms of their original contexts or else achieve optimal interpretive resemblance between two mental representations (passim).

The focus on a methodology that entailed the use of voice for collecting data from the working memories of participants would sideline interpreting, fostering further separation between 
Xiao, K. \& Muñoz, R. (2020). Cognitive Translation Studies: Models and methods at the cutting edge. Linguistica Antverpiensia, New Series: Themes in Translation Studies, 19, 1-24

their lines of work. With the newcomers into the recently established TS making it drift rapidly towards the humanities, interpreting researchers experienced a rise of pro-independence arguments, coined the label Interpreting Studies and, ultimately, founded the journals The Interpreters' Newsletter in 1988 and Interpreting in 1996. Ever since Ingrid Pinter (Kurz) finished her first-ever dissertation on interpreting in 1969, interpreting researchers had been moderately interested in neurological aspects while their translation counterparts had ignored them, so as to foster parallels with Al. It was not until a research group in Trieste formed around Fabbro and Gran (e.g., 1994, 1997) made neuroscientific aspects of interpreting the very core of their research that the brain made its way onto the CTIS scene. However, there was a new player in the field: community interpreting. Brian Harris (e.g., 1977) promoted the new conference series, The Critical Link, and the center of gravity of interpreting research would begin to move towards sociological approaches.

Meanwhile, TS was also thriving: Target was founded in 1989; the EST in 1992; Perspectives in 1993; The Translator in 1995. CTIS researchers studying translation in turn felt the pressure and coined the label Process Studies, as opposed to "product studies", which soon became the now outdated touchstone to distinguish CTIS from the rest of TS. Out of the many merits of this second generation of researchers we would like to underscore the soft, data-driven move from introspective to observational procedures and the strong commitment to empiricism that has been a distinctive feature of CTIS ever since.

A third phase seems to have started symbolically in the mid-1990s, at the time when two more conferences opened promising venues and steered progress towards reunification. The first one focused on interpreting and was held at Turku in 1994 (see Gile, 1995b); that fostered scientific research and multidisciplinarity. The second conference was the seventh Kent Psychology Forum (Danks et al., 1997), which staged both a reunification of the translation and interpreting lines of work and a welcome-back of researchers from neighboring disciplines. It was becoming increasingly clear that cognitive approaches to written and oral multilectal mediated communication were better off together than apart, and also that neither linguistics nor psychology were separately enough to work as referential frameworks for them. When better data-collection methods were devised at the turn of the century, such as keylogging (e.g., Translog, Jakobsen \& Schou, 1999), the studies grew both in number and in the number of participants. Comparing different groups became the sign of the times, and notions from linguistics and psychology would mix from then on.

Most process models had been developed with (mainly, if not only) written translation in mind. In this period, one of the few models for interpreting to become popular, inspiring and influential was the efforts model postulated by Gile (1995a). Drawing on the notion from cognitive psychology of a limited processing capacity, Gile developed a triple-effort model (listening, production and short-term memory efforts) for simultaneous interpreting to help interpreters understand interpreting "difficulties and select appropriate strategies and tactics" (1995, p. 191). The model may have been superseded (cf. Seeber, 2011, 2013), but Gile (1999) argued that his goals had not been "[...] to describe the simultaneous interpreting process, but 
Xiao, K. \& Muñoz, R. (2020). Cognitive Translation Studies: Models and methods at the cutting edge. Linguistica Antverpiensia, New Series: Themes in Translation Studies, 19, 1-24

to account for errors and omissions [...]" (p. 154). In doing so, by focusing on the widespread interest in problem solving, he had aligned interpreting research back with translation research.

Also in 1995, Kiraly developed an integrated pedagogical model of social and cognitive translation processes. In this model, the social involvement of translators in acts of communication and their cognitive activities were intertwined. Kiraly (1995) suggested they should be investigated together. While the cognitive aspect in his model represented the then mainstream ideas in cognitive science and psycholinguistics, his inclusion of social aspects hinted at the role of social interactions and situational factors in translation. Five years later, Kiraly (2000) would denounce classical information-processing approaches to favor social constructivism. His move paralleled the work of Shreve, but also of several other researchers, including Halverson and Risku, who espoused different notions of the mind and its relationship with language and communication (Muñoz, 2016a, note 5).

CTIS was growing and diversifying. The first CTIS research groups were founded - such as LETRA (Belo Horizonte), PACTE (Barcelona), PETRA (Granada), TRAP (Copenhagen), TRAPROS (Stockholm) - and some of them, together with prominent "lone wolves", joined the first international (European) network, EXpert Probing through Empirical Research on Translation procesSEs (EXPERTISE), founded by Antin Fougner Rydning. Since the turn of the century, most international general TS conferences have had at least one panel devoted to CTIS. This includes those organized by IATIS, founded in 2004.

On 10 June 2005, Arnt L. Jakobsen founded the Centre for Research and Innovation in Translation and Translation Technology (CRITT) at the Copenhagen Business School, which he directed until 2014. In doing so, he started a fourth stage in the development towards CTIS. Under his leadership, CRITT researchers and some of their associates worked on two EUfunded projects: Eye-to-IT (2006-2009), which focused on empirical research that combined keylogging and eye-tracking, and Cognitive Analysis and Statistical Methods for Advanced Computer Assisted Translation (CASMACAT, 2011-2014), which aimed to develop an interactive and comprehensive translators' workbench whose professional users would become post-editors of the output of an integrated MT application. In contrast, a 2009 conference at the University Jaume I (Castellón, Spain) revived interest in Harris' (1997) notion of natural translation (Blasco \& Jiménez, 2011). The interest in non-professional translation and interpreting would catch on: in 2012, the University of Bologna hosted the first of a biennial series of conferences on non-professional interpreting and translation where cognitive approaches featured prominently.

The CRITT became the new worldwide hub for CTIS, very much as the University of Leipzig's IALT had once been. In translation, this stage was marked by the prevalence of Translation Process Research (TPR), a CTIS research strand seemingly unconcerned with its inherited information-processing foundations but with a very strong and welcome drive towards developing and testing the new technological tools of the trade for translators. In 2010, both Carl and Muñoz published the basics of two theoretical models. Carl's (2010) was an update and clarification of classical information-processing views, with non-selective, subliminal, 
Xiao, K. \& Muñoz, R. (2020). Cognitive Translation Studies: Models and methods at the cutting edge. Linguistica Antverpiensia, New Series: Themes in Translation Studies, 19, 1-24

dissipative word and phrase translation systems contributing to the task and regulated by a translation automaton flagging translation problems and whose activity could be measured in terms of entropy (Carl, Tonge \& Lacruz, 2019). Muñoz's (2010) was inspired by situated (4EA) cognition and did not have much impact then. His model conceives of translating as a fuzzy, situated human endeavor dynamically emerging from the metacognitively steered interaction of bilinguals with texts and the environment, favored by adaptive entrenchment (Muñoz \& González, in press). However, two further factors fostered an important leap forward. First, Halverson (2010) suggested a new, broader view of the field and coined Cognitive Translation Studies as an umbrella term that would welcome all strands in CTIS. Second, in the same year, Amparo Hurtado founded the international network TREC as a forum for promoting, sharing and disseminating CTIS research and fostering cooperation.

As in previous stages, a new period may have started with a symposium, held at Las Palmas de Gran Canaria in 2015 (Muñoz, 2016a) where researchers working on classical approaches together with others focused on ergonomics, human-computer interaction, addressees' reception, cognitive aspects of dialogue interpreting and qualitative approaches staged the widening of TPR into CTIS. In 2014, the Centre for Studies of Translation, Interpreting and Cognition (CSTIC) of the University of Macau had opened its doors, and has ever since carried out formidable work in expanding CTIS throughout continental China. In 2016, the Translation \& Cognition Center (TRA\&CO) of the University of Mainz at Germersheim was founded, which has bridged CTIS and neuroscientific approaches to bilingualism. This is also happening at the University of Stockholm and in the tandem between ZHAW and the University of Zurich.

At the start of the third decade of this century, CTIS is one of the most active and the fastestgrowing areas in TS (Jääskeläinen \& Lacruz, 2018). It boasts an expanding research community with quite a number of research centers and laboratories at universities around the globe, including the Center for Research and Innovation in Translation and Translation Technology (CRITT, Kent State University), the CSTIC (University of Macau), the Experimental Laboratory on Translation (LETRA, UFMG), the Laboratory for Multilectal Mediated Communication \& Cognition (MC2 Lab, University of Bologna), the research group Socio-Cognitive Translation Studies: Processes and Networks (SOCOTRANS, University of Vienna) and TRA\&CO (University of Mainz at Germersheim). Less formally structured foci of research but equally active in authoring ground-breaking CTIS studies can be found at universities in Antwerp, Beijing, Dublin, Geneva, Hong Kong, Poznań, Shanghai, Sydney, Warsaw and Zurich, to name but a few.

Today CTIS comprises different paradigms - such as Computational Translatology (Carl, 2010, 2013), often overlapping with the old label of Translation Process Research (Jakobsen, 2014) and Cognitive Translatology (Muñoz, 2010, 2017; Muñoz \& González in press) - various research domains, such as reception studies (Kruger et al., 2016; Szarkowska \& Gerber-Morón, 2018) and workplace studies (Ehrensberger-Dow, 2014; Risku, 2014; Teixeira \& O'Brien, 2017), and many particular topics, such as problem-solving (e.g., Nitzke, 2019), cognitive effort and load (e.g., Szarkowska et al., 2016; Vieira, 2014), attention and cognitive control (e.g., Dong \& Li, 2020), skill acquisition and development (e.g., Massey, 2019), stress management (e.g., Korpal, 2016), emotions (e.g., Rojo \& Ramos, 2016) and multimodality (e.g., Tuominen, et al., 2018). 
Xiao, K. \& Muñoz, R. (2020). Cognitive Translation Studies: Models and methods at the cutting edge. Linguistica Antverpiensia, New Series: Themes in Translation Studies, 19, 1-24

This is how we got here. This is where we are now.

\section{Here and now}

In their article, Mapping Cognitive Translation and Interpreting Studies: A bibliometric approach, Christian Olalla-Soler, Javier Franco Aixelà and Sara Rovira-Esteva offer an overview of the CTIS landscape based on scientometrics spanning 60 years (1956-2015) of publications. They retrieved from BITRA 2,128 publications on CTIS and 77,714 on the rest of TS, and built an ad hoc database for their statistical analysis. They mapped the historical evolution and disciplinary characteristics of CTIS, with a focus on the research topics, languages of publication, publication formats, authorship patterns, citation and productivity. Their data suggests that CTIS started to gather momentum at the end of 1970s; that most studies are based on linguistics and psychology; that eye-tracking and think-aloud account so far for almost half of the data-collection methods; that co-authorship in CTIS is more frequent than in TS, and that - unsurprisingly, in view of the fact that CTIS is a smaller but more focused research area - the CTIS documents receive more citations than TS documents. These findings support the view that CTIS is gaining its legitimacy as a sub-discipline of TS, as it has its own citation, authorship and readership patterns.

Our account of the evolution of CTIS was based on our interpretation of their data and aimed to outline the main thread lines of a history for CTIS that shows that, through calm and storm and with zigzags in the rudder, a growing team of ever more and ever more diverse rowers have joined efforts to reach the same disciplinary utopia. By Holmes' standards, these developments seem to suggest an emerging and increasingly autonomous body of knowledge. Still, however flattering it might be to declare CTIS an autonomous discipline, and however reasonable it may sound to argue for staying as a branch of TS, the issue simply misses the point. We are an applied, interdisciplinary endeavor and it is results, not pompous declarations, what will legitimize us. Sixty years of work have had a modest impact on translator and interpreter training, but have not led to many more contributions that are substantial. It may be a cliché to write that at this time we have learned to ask the right questions, but we still face challenges such as the need to build and test theoretical models to account for the peculiarities of translational cognition, and the critical assessment and streamlining of our research methods. The collection of articles in this volume of Linguistica Antverpiensia, New Series - Themes in Translation Studies dives into these areas.

\subsection{Framing and reframing CTIS}

In his masterplan design of TS as an autonomous discipline, Holmes (1972/2000) suggested a branch of process-oriented studies devoted to translation psychology or psycho-translation studies [sic]. As a multifaceted study of the human mind and behavior, psychology is more inclusive than what Translation Process Research implied. Jääskeläinen (2012) suggests that translation psychology comprises not only the translating mind, but also the mental workings of cognition, affect and emotion. It also studies translators' social interaction and readers' response to the translated product (namely, reception studies). Jääskeläinen (2012) concludes that "there is a psychological angle to most translation-related phenomena" (p. 192) and that a 
Xiao, K. \& Muñoz, R. (2020). Cognitive Translation Studies: Models and methods at the cutting edge. Linguistica Antverpiensia, New Series: Themes in Translation Studies, 19, 1-24

translation psychology can be a very fruitful multi-disciplinary research field. Bolaños' (2016) understanding of translation psychology is even more inclusive, covering the translators' emotional, cognitive, behavioral and social factors at play while translating.

Lin Zhu, in her paper A Critical Review of the Research on Translation Psychology: Theoretical and Methodological Approaches, offers a critical review of different research frameworks within the sphere of such a translation psychology. She identifies four approaches to translation psychology: cognitive, social, Gestalt and embodied. Zhu hints at integrated research on translation psychology, with the translator as the center to highlight embodied cognition and social interactions, a position that rules out the study of other participants in communicative events.

Translators and interpreters were once compared to bilinguals and are now often described as trained bilinguals. Several scholars (e.g., Diamond \& Shreve, 2010; Halverson, 2013) have called for integrating bilingualism with translation, but research in this area remains scarce. In the article Current Research in Bilingualism and its Implications for Cognitive Translation and Interpreting Studies, John W. Schwieter, Julia Festman and Aline Ferreira discuss research on some concepts and constructs from bilingualism that hold promise to complement both empirical research and theoretical models in CTIS - namely, lexical access, the multilingual mental lexicon, language regulation and control, and the debate on a bilingual advantage. Of particular interest for CTIS researchers are the questions of how a purported bilingual mental lexicon might be organized and accessed, and how the bilinguals manage two languages at once. In turn, CTIS may help bilingualism in apprehending cognitive advantages in bilinguals that seem related to use rather than the mere fact of speaking two languages. Schwieter, Festman and Ferreira also suggest some potential areas for research, including directionality ( $\mathrm{L} 2 \rightarrow \mathrm{L} 1$ or $\mathrm{L} 1 \rightarrow \mathrm{L} 2)$ in translation, and multilinguals' individual differences in performance. They conclude that research on bilingualism and CTIS has a fruitful interface and that the empirical research on the way in which various bilingual experiences are linked to translation performance and other higher processing demands holds promise.

The social front of CTIS is also expanding. Several scholars - especially, Hanna Risku - have used some socio-cognitive models such as Latour's (2007) Actor Network Theory (Buzelin, 2005) and Schweizer's (1996) dynamic network model to take in both environmental and mental aspects in the analysis (e.g., Risku, 2014). Most cognitive approaches to translation seem to hold a view that the mental processes and the social processes are separate entities (such as in the information-processing paradigm) or that one is embedded in the other, as suggested in the distinction between acts and events (but see Muñoz, 2016b). Nevertheless, they both adopt a perspective centered on the individual. Based on the notion that human cognition is fundamentally social and relational and that there is no clear-cut break between an individual mind and its social environment, the article Social Representations Theory: An Approach to Studying Translators' Socio-Cognitive Processes by Sari Hokkanen suggests a model of social representation to study translators' socio-cognitive processes. According to Moscovici's (1984) social representations theory, in our knowledge construction, the unfamiliar is made familiar through the processes of anchoring and objectification, while 
Xiao, K. \& Muñoz, R. (2020). Cognitive Translation Studies: Models and methods at the cutting edge. Linguistica Antverpiensia, New Series: Themes in Translation Studies, 19, 1-24

social representations are formed and adapted through three intertwined processes: sociogenesis (at the level of social groups), ontogenesis (at the level of individuals) and microgenesis (through social interactions). Hokkanen shows how social representations theory could be applied to analyze translators' conceptualizations of ST authors and TT readers and argues that this theory offers a comprehensive theoretical model for studying the social construction of knowledge with an integration of individuals, social groups, and the social interaction and embodied actions that link individuals to the social environment. It is no doubt an innovative theoretical model that merits further empirical support.

\subsection{Validity and reliability of CTIS research}

Validity, according to Guba and Lincoln (2005), is a criterion by which to judge whether one's research findings are "sufficiently authentic that I may trust myself in acting on their implications" (p. 205). It is the degree to which results match the real state of the world (Saldanha \& O'Brien, 2014). There are at least three types of threat to validity: internal, external and problems regarding measurement (Frey et al., 1991). Internal threats are posed by the researcher, the participant or the manner in which the research is conducted. External threats are related to ecological validity or replication. In CTIS, the focus is on people (mediators and other participants) and the process, so that both internal and external threats are of crucial importance. For example, the Hawthorne effect (Saldanha \& O'Brien, 2014) - also known, with variations, as the Heisenberg effect, observer's paradox or white coat effect - explains that translators may alter their normal behavior when they are aware that they are being studied.

One of the differences between the laboratory and ethnographic approaches to studying translational cognition is the role of the researcher in the process. In controlled laboratory experiments, the researcher is a bystander and controller of the research who does never get involved in the activities and settings. In ethnographic investigations, however, research methods include participant observation and field interviews that encourage a "high degree of personal involvement from the researchers" (Saldanha \& O'Brien, 2014, p. 209). That is, the researcher becomes a part of the object of study. Thus, the ethnographic research into translation processes also entails some questions about the relationship between researchers and participants - for example, what the attitudes are of participants towards the researchers. In their article, Situated Cognition and the Ethnographic Study of Translation Processes: Translation Scholars as Outsiders, Consultants and Passionate Participants, Jelena Milošević and Hanna Risku offer some answers to these questions, based on their ethnographic study in four workplace settings: two freelance translators working together, a translation agency, the technical document department of a technology company and the translation department of a public institution. They used handwritten notes, drawn sketches of the work settings and semistructured interviews as raw data to carry out a qualitative content analysis of participants' reactions to the researchers' request to participate, their perceptions and their expectations of the researchers. Their findings suggest that, while the participants predominantly perceive the researchers as "others", their specific attitudes towards them differ - for example, regarding them as academic authorities, translation consultants, interested scientists, passionate participants, spies or uninformed learners. Based on their findings, Milošević and Risku suggest 
Xiao, K. \& Muñoz, R. (2020). Cognitive Translation Studies: Models and methods at the cutting edge. Linguistica Antverpiensia, New Series: Themes in Translation Studies, 19, 1-24

that building trust and fostering connections between researchers and participants are crucial in overcoming some of the challenges in the ethnographic studies of translation processes.

The role of the researcher and the artificiality of the setting in think-aloud techniques have been a primary concern for decades now. Ecological validity deals with how to make research reflect real-life situations, at least in such a way that research results can be generalized to such situations. Jääskeläinen (2017) suggests that in any research that is not purely observational, ecological validity is always an issue, and that "thinking aloud compromises ecological validity the most" (p. 218). Veridicality is a criterion often used to refer to the effects of think-aloud techniques - also referred to as concurrent verbal reports or as thinkaloud protocols (TAPs, for short). This technique was devised for much simpler tasks and much shorter time spans, so the probability that "processes underlying behavior may be unconscious and thus not accessible for verbal reporting" and the "possibility that verbalizations may not be closely related to the underlying thought processes" (Ericsson \& Simon, 1993, p. 109) is in our case close to a certainty.

House (2013) questioned the validity and reliability of verbal reporting and raised questions about their behavioral measurement. She expressed strong doubts about the assumption that persons involved in translating have substantial control over their mental processes and that these mental processes are accessible to them. The root of the problem seems to lie in the somewhat naïve assumption that one's own stream of thoughts can be accessed and reproduced linearly and "verbatim". Yet, whatever the mediators describe and explain can be taken as clues to what goes on in their minds and can shed light on their task conception and awareness, which in turn have a clear influence on their behavior. That is why think-aloud techniques are still in use and, especially, why cued retrospective protocols are very popular in multi-method research projects, as a source with which to support researchers' interpretations of data. Sanjun Sun, Tian Li and Xiaoyan Zhou wrote the article Effects of Thinking Aloud on Cognitive Effort in Translation to respond to objections that thinking aloud may interfere with the translation process (e.g., Toury, 1991) and affect the translation product (Hansen, 2005) to test to what extent it might slow down translating, as observed by Jakobsen (2003), and what variables may be involved. They studied the effects of thinking aloud on cognitive effort in translation trainees through time on task, duration of the translation phases, cognitive effort of processing ST and TT, and the quality of translation. They contrasted participants translating silently and while thinking aloud. Their findings suggest that thinking aloud has a significant influence on translation duration; that it has various effects on cognitive effort, depending on the ST difficulty and on the different translation stages; and that it has no effect on the quality of translations of difficult texts. Sun, Li and Zhou's research suggests that the negative effects of thinking aloud on the translation process are still open to discussion, and that diversified effects might be observed when more variables are taken into account.

Retrospection is the mandatory introspective method in interpreting research. Compared with concurrent verbalizations, retrospection is assumed to be less invasive (Buchweitz \& Alves, 2006). However, critics have challenged the validity, completeness and veridicality of verbal data gathered through retrospection. One of the factors at stake is the methods to cue 
Xiao, K. \& Muñoz, R. (2020). Cognitive Translation Studies: Models and methods at the cutting edge. Linguistica Antverpiensia, New Series: Themes in Translation Studies, 19, 1-24

participants' retrieval from memory. In her article, Retrospective Protocols in SI: Testing the Effect of Retrieval Cues, Ewa Gumul reports her findings on the effects of two popular retrieval cueing methods on interpreters' verbal reporting: source-text transcripts versus target-text recordings. Based on the analysis of the informativeness, accuracy and verbosity of the retrospective reports, Gumul finds no outstanding differences between them. Other variables might need to be taken into account, such as visual or auditory dominance, which is a potential topic for future research.

Reliability is the extent to which research can be replicated, which means that other researchers can generate the same results if they use the same methods to investigate the same questions at a different time (Saldanha \& O'Brien, 2014). A method or measurement tool has higher reliability if it offers stable and consistent results in repeated research (Mellinger \& Hanson, 2017). Reliability is also linked to reproducibility, the extent to which a certain research project can be checked step by step to determine the quality of its results.

In Methodological Considerations for Survey Research: Validity, Reliability, and Quantitative Analysis, Christopher D. Mellinger and Thomas A. Hanson critically review the dataelicitation tools used in the research literature to find that surveys have so far not played a prominent role in CTIS. They argue that we need to use surveys to gather information about participants' attitudes, behaviors, perceptions and values. They focus on three crucial issues in survey research for CTIS, namely, validity, reliability and quantitative analysis. As for validity, the article discusses the notions of content, criterion and construct validity. Regarding reliability, Mellinger and Hanson emphasize three potential sources of trouble: online administration, translation of survey responses and cross-cultural difference in data collection. For the quantitative analysis of the survey data, they highlight three common errors - singleitem comparison, disbelief in standard parametric analyses and inappropriate choice of statistical method. In addition, Mellinger and Hanson emphasize the importance of building a link between theoretical frameworks and methodological work, a crucial reminder for today's CTIS researcher.

\subsection{Novelties in methods}

Two trends are emerging in CTIS methodology: the broader use of physiological measures (Shreve \& Diamond, 2016) and the consolidation of multimethod strategies (Halverson, 2017). The increasing adoption of physiological measures is consistent with the growing interest in psycho-affective factors such as stress and emotions. These methods can still be seen more often in the research on interpreting (Korpal \& Jasielska, 2019), audiovisual translation (Ramos, 2015) and media accessibility. Diamond and Shreve (2010) suggested a wider adoption of neurological and physiological methods to broaden our possibilities, on the grounds that data collection through keylogging and eye-tracking had by then been well established in CTIS. The use of neurological methods is on the rise and physiological measures have expanded to include temperature, heart rate (HR), heart-rate variability (HRV) and skin conductance (SC). We need to develop protocols on the specific application of these tools to achieve a more fruitful application (Shreve \& Diamond, 2016). There is, for example, a need 
Xiao, K. \& Muñoz, R. (2020). Cognitive Translation Studies: Models and methods at the cutting edge. Linguistica Antverpiensia, New Series: Themes in Translation Studies, 19, 1-24

to define measurement and analysis parameters, such as $H R$ versus RHV, and to critically assess the merits and limitations of applying these methods in CTIS (e.g., there is some important interpretive distance between measured arousal and inferred emotions). To this end, Ana María Rojo López and Paweł Korpal offer in Through Your Skin to Your Heart and Brain: A Critical Evaluation of Physiological Methods in Cognitive Translation \& Interpreting Studies a critical evaluation of three physiological indicators: HR, HRV and skin conductance. These indicators are usually adopted to test the stress and emotions that participants experience, whether they are at a task or as the audience of audiovisual materials. They focus on the nature of these methods, what they measure, how they should be applied, how the analysis should be made and what threats they present to the validity of the research. They also discuss ethical issues - such as the intrusiveness of HRV, respect for personal privacy and the protection of data - and the triangulation of HR/HRV and SC with other measures in the research on emotion processing in translation. This makes their contribution a practical, informative and much-needed hands-on introduction to two of these measures. They suggest that HR and SC are more economical, pain-free and less invasive than other sophisticated measures, such as EEG. Their critical review may be used as a guideline by researchers interested in emotions and will definitely contribute to the more fruitful adoption of physiological methods in CTIS.

In contrast, multi-method strategies, that is, combinations of several (mostly) data-collection methods to elicit different kinds of data, seem to have become the norm (Alves \& Hurtado, 2017; Halverson, 2017). Multi-method research is often confused with mixed methods research and triangulation. Mixed-method projects are those that combine quantitative and qualitative data. Since they imply the use of at least two methods, all mixed-method projects are also multi-method, but many multi-method projects cannot be described as mixed methods because they combine either (at least two) quantitative or qualitative methods. Triangulation is the use of two quantitative data-collection methods to collect one and the same kind of data to cancel out error in one or both methods, or to fill potential gaps. For instance, screen recording may be combined with keylogging; backtracking moves that go far from the current insertion point can be better and easier discerned in the screen record than in the log. As another example, pupil dilation or electro-dermal activity may be triangulated to measure cognitive effort. Research projects today are mainly multi-method endeavors that often combine interviews, verbal reports, keylogging, eye-tracking and neurological and physiological measures. Halverson (2017) suggests taking a problem's demands as the starting point.

With a focus on the methodology to study the effects of time pressure on translation task performance, Yu Weng and Binghan Zheng propose in A Multi-Methodological Approach to Studying Time-Pressure in Written Translation: Manipulation and Measurement a framework for time pressure manipulation and measurement. They review the existing literature on the research of translating under time pressure and find that it is induced by constraining the given timeframe. They present three subjective strategies of manipulating time pressure: giving pre-task time instructions, increasing participants' intrinsic motivation, and visualizing the elapsing time. As for measurement, they critically discuss Bayer-Hohenwarter's (2009) approach, which they argue could be refined. They propose a multimethod framework for 
Xiao, K. \& Muñoz, R. (2020). Cognitive Translation Studies: Models and methods at the cutting edge. Linguistica Antverpiensia, New Series: Themes in Translation Studies, 19, 1-24

measuring time pressure, including physiological, psychological and behavioral measures. They offer a detailed introduction to the three types of measurement and a critical discussion on the the strategies to manipulate and the methods to measure time pressure in translation.

The last contribution in the volume focuses on measuring the participants' working memory (WM), so it might be deemed more classical. WM is closely related to language use, especially in bilingual and multilingual activities, and has been a prominent topic in the research of interpreting and language learning (Schwieter \& Ferreira, 2017; Timarová, 2008). Interpreters are assumed to develop specific ways of using WM more efficiently so that they can simultaneously process linguistic input, lexical and semantic access, reformulation and the production of the translation excerpt (Bajo et al., 2001; Ransdell et al., 2006). Jie Li carried out two tests on 33 Chinese translation students with the language pair of English-Chinese to investigate their storage spans, the processing capacity of their verbal WM and their correlations with translation speed and quality. She reports about them in the article The Impact of Verbal Working Memory on Written Translation: Empirical Evidence and an Initial Model. In the first test, E-Prime software was applied to measure the translation students' processing and storage capacities of verbal WM in L1 (Chinese) and L2 (English). In the second test, students' keystroke data were logged while they were translating and the quality of their translations was evaluated. Her findings suggest that there is a positive correlation between the storage span and the processing capacity of their verbal WM in L1 and L2, but also that language specificity is obvious, with better performance in L1 than in L2. Li also finds that in the direction of $L 2 \rightarrow L 1$ translation, the processing capacity of $L 2 W M$ has a positive effect on translation speed whereas the L1 processing capacity has no effect on the quality of translation. This is one of the few experimental research projects on the measurement of translators' WM and its effect on translation performance in terms of speed and quality, and it raises questions about the role of WM in the translation process.

\section{Closing remarks}

CTIS is growing up, but is not yet coming of age. Since the 1960s, it has experienced ups and downs and is now back at full cruising speed, partly because of the hasty progress being made in high-tech communications and improved research tools. In the midst of this new stage, we should lean back to reflect on some fundamental issues. In spite of all the technological hype, a machine translation is technically not a translation (there is no processing of meaning involved) but a great statistical artifice with which to yield the most likely translation, one that only a knowledgeable human being can sanction as such. This in no way challenges the excellent results of MT systems, especially so-called neural MT systems. We simply suggest that redressing our views on the nature and functions of MT might be beneficial in translator training, translators' everyday work and in the very development of such systems. Computers were designed to mimic the way researchers in the 1950s thought human minds work. But we know now that minds and brains do not work that way. Neural networks, for instance, only partially mimic one kind of neural network. Their results are spectacular, but they still make basic mistakes because they do not understand, and do not have a singular point of view based on experience and adapted to socially shared views through interaction. It is 
Xiao, K. \& Muñoz, R. (2020). Cognitive Translation Studies: Models and methods at the cutting edge. Linguistica Antverpiensia, New Series: Themes in Translation Studies, 19, 1-24

therefore very likely that MT systems and CAT tools will keep improving - and keep making basic mistakes. We need a deep understanding of the human mind and to redefine humancomputer interaction. Post-editing may be more productive as a result, but it is also mentally much more effortful and may require other working schedules and certainly improvements in the systems interfaces. There is plenty of work ahead, since our most basic constructs are often little more than ill-understood metaphors, as in the case of cognitive load.

Digital person-to-person (P2P) communications are here to stay, and they are fostering a growth in the demand that no MT system can meet, and not only because a considerable part of such demand cannot be monetized. P2P communications have made it possible to do without some intermediaries (some online hubs allow project managers to bid directly for jobs, sometimes making even translation companies superfluous). In spite of recurrent fears experienced by translation and interpreting trainees, the job market is also experiencing a relatively steep rise, but it will not be enough either. Online interest groups may boost some professional specializations (e.g., emergency interpreting) and lead to new ones (e.g., translating classical music concert programs), but the demand is far larger than that. Now people may access all kinds of information offered in other languages that they may be interested in but not necessarily so much as to spend their money on it. For instance, beach volleyball, collectibles, old Eastern European cartoons, etc. Hence fansubbing and crowdsourced translations. We are heading towards translation becoming the fifth skill - not as a part of language learning but, rather, as a part of everyday communications. This does not mean that we will all be translators beyond our natural abilities. Quite the contrary, the training of translators, whether at schools or at work, is taking longer and becoming more complex. The times are gone when simply speaking two languages and having a decent cultural stock would get you a job as a translator, and it is precisely IC technologies that underscore the need for specific training to meet market demands. What we mean is that all citizens will have to develop a translation culture, a sort of translation and MT literacy. We spent decades beating about the bush on clients' education, only to find ourselves now facing the formidable challenge of educating everyone about how to deal with translators and translations, how to determine their quality, how to use MT systems on their own and cope with uneven results. And the how is the natural realm of CTIS.

We are also going to find more and more hybrid communication systems combining features of oral, written and signed languages with other codes. Now that we are also overcoming the divide between linguistics and psychology, we need to face the fact that the palette of multilectal mediated communication tasks is full of hybrids and that the dichotomy of pure oral and pure written mediation is becoming a mirage. Our digital tools of the trade, those that pump up our productivity, ensure consistency and take care of the boring, repetitive bits of texts, also demand more cognitive effort, so there is a certain trade-off that we should be exploring. Remote interpreting makes it possible to provide overdue social and community services, but we know very little about the cognitive specifics of using these systems and the consequences it may have on the quality of communication and the outcomes of important communicative events. CTIS has grown used to comparing translation trainees, untrained bilinguals and professionals; we studied people working on different kinds of text or facing speakers at different 
Xiao, K. \& Muñoz, R. (2020). Cognitive Translation Studies: Models and methods at the cutting edge. Linguistica Antverpiensia, New Series: Themes in Translation Studies, 19, 1-24

rates of delivery. This is fine and we should continue to do so, only with clearer theories supported by more rigorous research efforts, the two thread lines woven in this issue.

However, in the dawn of this multimodal era we also need to study and contrast both related and unrelated multilectal mediation tasks to discern the cognitive processes involved in improving or achieving communication and focus on their roles, their interaction, their entrenchment, rather than on purported memory, control, and bilingual advantages that apparently separate translators and interpreters from ordinary mortals but which do not really explain much. We also need to keep but go way beyond mean performance measures, because they will always conceal or miss important information. Translational cognition can be ascertained only in the situated behavioral dynamics of human beings interacting with their environments while engaged in multilectal mediated communication events. We need to study what happens in longer texts, focus on time-to-event data, and do so at different timescales, including those where quantification is not only impractical, but also uninteresting. Intra-subject curves on response times, fixation durations, typos, decalage and information searches may shed light on cognitive processes because today's measurements cannot reduce much of interpersonal variation. We need more longitudinal studies, today unfairly relegated to oblivion due to pressure on the pace of researchers' career advancement. We need more naturalistic research, preferably combined with studies under experimental conditions, but we mainly need to bring the world into the lab, and basic testing to the web, to build random samples whose numbers we can only dream of today.

This is what we think we should be reflecting on while we read the excellent and varied contributions to this issue of Linguistica Antverpiensia, New Series: Themes in Translation Studies that we have had the honor to co-edit. One of the nicest things about working in CTIS is the constant feeling that everything remains to be done and that the best is yet to come.

\section{Funding}

This work was partially supported by National Social Science Foundation of China (grant number 17BYY048). 
Xiao, K. \& Muñoz, R. (2020). Cognitive Translation Studies: Models and methods at the cutting edge. Linguistica Antverpiensia, New Series: Themes in Translation Studies, 19, 1-24

\section{References}

Alves, F., \& Hurtado Albir, A. (2017). Evolution, challenges, and perspectives for research on cognitive aspects of translation. In J. W. Schwieter \& A. Ferreira (Eds.), The handbook of translation and cognition (pp. 537-554). Wiley-Blackwell. https://doi.org/10.1002/9781119241485.ch29

Alves, F., Hurtado Albir, A., \& Lacruz, I. (Eds.). (2015). Translation as a cognitive activity [Special issue]. Translation Spaces, 4(1). https://doi.org/10.1075/ts.4.1

Alves, F., \& Jakobsen, A. L. (Eds.). (2020). The Routledge handbook of translation and cognition. Routledge. https://doi.org/10.4324/9781315178127

Bajo Molina, M.T., Padilla Benítez, P., Muñoz Martín, R., Padilla, F., Gómez, C., Puerta, C. M., Gonzalvo, P., \& Macizo, P. (2001). Comprehension and memory processes in translation and interpreting. Quaderns: Revista de Traducció, 6, 27-31.

Bayer-Hohenwarter, G. (2009). Methodological reflections on the experimental design of timepressure studies. Across Languages and Cultures, 10(2), 193-206. https://doi.org/10.1556/Acr.10.2009.2.2

Bell, R. T. (1991). Translation and translating: Theory and practice. Longman.

Blasco Mayor, M. J., \& Jiménez Ivars, A. (Eds.). (2011). Interpreting naturally: A tribute to Brian Harris. Peter Lang. https://doi.org/10.3726/978-3-0351-0306-9

Bogucki, Ł. (2020). A relevance-theoretic approach to decision-making in subtitling. Springer. https://doi.org/10.1007/978-3-030-51803-5

Bolaños Medina, A. (2016). Translation psychology within the framework of translator studies: New research perspectives and pedagogical implications. In C. Martín de León \& V. González-Ruiz (Eds.), From the lab to the classroom and back again: Perspectives on translation and interpreting training (pp. 59-100). Peter Lang.

Buchweitz, A., \& Alves, F. (2006). Cognitive adaptation in translation: An interface between language direction, time, and recursiveness in target text production. Letras de Hoje 41, 241-272.

Buzelin, H. (2005). Unexpected allies: How Latour's network theory could complement Bourdieusian analyses in translation studies. The Translator, 11(2), 193-218. https://doi.org/10.1080/13556509.2005.10799198

Carl, M. (2010). A computational framework for a cognitive model of human translation processes. Proceedings of the $32^{\text {nd }}$ International Conference on Translating and the Computer. 18-19 November 2010, London. http://mt-archive.info/Aslib-2010-Carl.pdf

Carl, M. (2013). A computational cognitive model of human translation processes. In S. Bandyopadhyay, S. K. Naskar \& A. Ekbar (Eds.), Emerging applications of natural language processing: Concepts and new research (pp.110-128). IGI Publishing. https://doi.org/10.4018/978-1-4666-2169-5.ch005

Carl, M., Bangalore, S., \& Schaeffer, M. (Eds.). (2016). New directions in empirical translation process research. Exploring the CRITT TPR-DB. Springer. https://doi.org/10.1007/978-3-319-20358-4

Carl, M., Tonge, A., \& Lacruz, I. (2019). A systems theory perspective on the translation process. Translation, Cognition \& Behavior, 2 (2): 211-232. https://doi.org/10.1075/tcb.00026.car

Danks, J. S., Shreve, G. M., Fountain, S. B., \& McBeath, M. K. (Eds.) (1997). Cognitive processes in trans/ation and interpreting. Sage Publications.

Diamond, B. J., \& Shreve, G. M. (2010). Neural and physiological correlates of translation and interpreting in the bilingual brain: Recent perspectives. In G. M. Shreve \& E. Angelone (Eds.), Translation and cognition (pp. 289-322). John Benjamins. https://doi.org/10.1075/ata.xv.16dia

Dong, Y., \& P. Li. (2020). Attentional control in interpreting: A model of language control and processing control. Bilingualism: Language and Cognition, 23(4), 716-728. https://doi.org/10.1017/S1366728919000786 
Xiao, K. \& Muñoz, R. (2020). Cognitive Translation Studies: Models and methods at the cutting edge. Linguistica Antverpiensia, New Series: Themes in Translation Studies, 19, 1-24

Ehrensberger-Dow, M. (2014). Challenges of translation process research at the workplace. MonTI, 7(2), 355-383. https://doi.org/10.6035/MonTI.2014.ne1.12

Ehrensberger-Dow, M., \& Englund Dimitrova, B. (Eds.). (2016). Cognitive space: Exploring the situational interface [Special issue]. Translation Spaces, 5(1). https://doi.org/10.1075/ts.5.1

Ehrensberger-Dow, M., Englund Dimitrova, B., \& Hubscher-Davidson, S. (Eds.). (2014). The development of professional competence [Special issue]. Translation and Interpreting Studies, 9(1). https://doi.org/10.1075/tis.9.1

Ehrensberger-Dow, M., Englund Dimitrova, B., Hubscher-Davidson, S., \& Norberg, U. (Eds.). (2015). Describing cognitive processes in translation. Acts and events. John Benjamins. https://doi.org/10.1075/bct.77

Enríquez Raído, V. (2014). Translation and Web Searching. Routledge. https://doi.org/10.4324/9780203798034

Ericsson, K. A., \& Simon, H. A. (1980). Verbal reports as data. Psychological Review, 87(3), 215-251. https://doi.org/10.1037/0033-295X.87.3.215

Ericsson, K. A., \& Simon, H. A. (1993). Protocol analysis: Verbal reports as data. MIT Press. https://doi.org/10.7551/mitpress/5657.001.0001

Fabbro, F., \& Gran, L. (1994). Neurological and neuropsychological aspects of polyglossia and simultaneous interpretation. In S. Lambert \& B. Moser-Mercer (Eds.), Bridging the gap: Empirical research in simultaneous interpretation (pp. 273-317). John Benjamins. https://doi.org/10.1075/btl.3.21fab

Fabbro, F., \& Gran, L. (1997). Neurolinguistic aspects of simultaneous interpretation. In Y. Gambier et al. (eds.) Conference interpreting: Current trends in research (pp. 9-27). John Benjamins. https://doi.org/10.1075/btl.23.02fab

Ferreira, A. \& Schwieter, J. W. (Eds.). (2015). Psycholinguistic and cognitive inquiries into translation and interpreting. John Benjamins. https://doi.org/10.1075/btl.115

Frey, L. R., Botan, C. H., \& Kreps, G. L. (1991). Investigating communication: An Introduction to research methods. Prentice Hall.

García, A. M. (2019). The neurocognition of translation and interpreting. John Benjamins. https://doi.org/10.1075/btl.147

García, A. M., \& Giozza, M. C. (Eds.). (2019). Cognitive explorations of translation and interpreting [Special issue]. Perspectives, 27(4).

Gerver, D., \& Sinaiko, H. W. (1978). Language interpretation and communication. Plenum Press. https://doi.org/10.1007/978-1-4615-9077-4

Gile, D. (1995a). Basic concepts and models for interpreter and translator training. John Benjamins. https://doi.org/10.1075/btl.8(1st)

Gile, D. (1995b). Interpretation research: A new impetus? Hermes, 14, 15-29. https://doi.org/10.7146/hjlcb.v8i14.25100

Gile, D. (1999). Testing the Effort Models' tightrope hypothesis in simultaneous interpreting-A contribution. HERMES, 12(23), 153-172. https://doi.org/10.7146/hjlcb.v12i23.25553

Giozza, M., Jääskeläinen, R., Mellinger, C. D., \& Rodríguez-Inés, P. (Eds.). (2015). Translation process research [Special issue]. Translation \& Interpreting, 7(1).

Guba, E. G., \& Lincoln, Y. S. (2005). Paradigmatic controversies, contradictions, and emerging influences. In N. K. Denzin \& Y. S. Lincoln (Eds.), The Sage handbook of qualitative research 3rd ed. (pp. 191-216). Sage Publications.

Gutt, E.-A. (1991). Translation and relevance: Cognition and context. Blackwell.

Halverson, S. L. (2010). Cognitive Translation Studies: Developments in theory and method. In G. M. Shreve \& E. Angelone (Eds.), Translation and cognition (pp. 349-369). John Benjamins. https://doi.org/10.1075/ata.xv.18hal 
Xiao, K. \& Muñoz, R. (2020). Cognitive Translation Studies: Models and methods at the cutting edge. Linguistica Antverpiensia, New Series: Themes in Translation Studies, 19, 1-24

Halverson, S. L. (2013). Implications of Cognitive Linguistics for translation studies. In A. Rojo \& I. Ibarretxe-Antuñano (Eds.), Cognitive Linguistics and translation: Advances in some theoretical models and applications (pp. 31-73). Mouton de Gruyter.

Halverson, S. L. (2017). Multimethod approaches. In J. W. Schwieter \& A. Ferreira (Eds.), The handbook of translation and cognition (pp. 195-212). Wiley-Blackwell. https://doi.org/10.1002/9781119241485.ch11

Halverson, S. L., \& Muñoz Martín, R. (2020). The times, they are a-changin'. Multilingual mediated communication and cognition. In R. Muñoz \& S. Halverson (Eds.), Multilingual mediated communication and cognition (pp. 1-17). Routledge. https://doi.org/10.4324/9780429323867$\underline{1}$

Hansen, G. (2005). Experience and emotion in empirical translation research with think-aloud and retrospection. Meta, 50(2), 511-521. https://doi.org/10.7202/010997ar

Hansen-Schirra, S., Czulo, O., \& Hofmann, S. (Eds.). (2017). Empirical modelling of translation and interpreting. Language Science Press. https://doi.org/10.5281/zenodo.1089335

Harris, B. (1977). The importance of natural translation. Working Papers on Bilingualism, 12, 96-114.

Holmes, J. S. (1972/2000). The name and nature of translation studies. In L. Venuti (Ed.) The Translation Studies reader (pp. 172-184). Routledge.

House, J. (2013). Towards a new linguistic-cognitive orientation in translation studies. Target, 25(1), 46-60. https://doi.org/10.1075/target.25.1.05hou

House, J., \& Blum-Kulka, S. (1986). Interlingual and intercultural communication: Discourse and cognition in translation and second language acquisition. Gunter Narr.

Hubscher-Davidson, A. (2017). Translation and emotion. A psychological perspective. Routledge. https://doi.org/10.4324/9781315720388

Hurtado Albir, A. (Ed.). (2017). Researching translation competence by PACTE group. John Benjamins. https://doi.org/10.1075/btl.127

Jääskeläinen, R. (2012). Translation psychology. In Y. Gambier \& L. van Doorslaer (Eds.), Handbook of translation studies (Vol.3, pp. 191-197). John Benjamins. https://doi.org/10.1075/hts.3.tra14

Jääskeläinen, R. (2017). Verbal reports. In J. W. Schwieter \& A. Ferreira (Eds.), The handbook of translation and cognition (pp. 213-231). Wiley-Blackwell. https://doi.org/10.1002/9781119241485.ch12

Jääskeläinen, R., \& Lacruz, I. (2018). Translation - cognition - affect - and beyond. Reflections on an expanding field of research. In I. Lacruz \& R. Jääskeläinen (Eds.), Innovation and expansion in translation process research (pp. 1-16). John Benjamins. https://doi.org/10.1075/ata.18.01jaa

Jäger, G. (1975). Translation und Translationslinguistik. Niemeyer.

Jakobsen, A. L. (2003). Effects of think aloud on translation speed, revision, and segmentation. In F. Alves (Ed.), Triangulating translation: Perspectives in process oriented research (pp. 69-95). John Benjamins. https://doi.org/10.1075/btl.45.08jak

Jakobsen, A. L. (2014). The development and current state of translation process research. In L. van Doorslaer, R. Meylaerts \& E. Brems (Eds.), The known unknowns of translation studies (pp. 6588). John Benjamins. https://doi.org/10.1075/bct.69.05jak

Jakobsen, A. L., \& Mesa Lao, B. (Eds). (2017). Translation in transition: Between cognition, computing and technology. John Benjamins. https://doi.org/10.1075/btl.133

Jakobsen, A. L., \& Schou, L. (1999). Translog Documentation Version 1.0. In G. Hansen (Ed.), Probing the process of translation: Methods and results (Appendix 1, pp. 1-36). Copenhagen Studies in Language 24. Samfundslitteratur.

Kade, O. (1968). Zufall und Gesetzmäßigkeit in der Übersetzung. VEB Verlag Enzyklopädie.

Kiraly, D. (1995). Pathways to translation: Pedagogy and process. The Kent State University Press. 
Xiao, K. \& Muñoz, R. (2020). Cognitive Translation Studies: Models and methods at the cutting edge. Linguistica Antverpiensia, New Series: Themes in Translation Studies, 19, 1-24

Kiraly, D. (2000). A social constructivist approach to translator education. Empowerment from theory to practice. St. Jerome.

Klimant, P., Tieber, M., \& Risku, H. (Eds.). (2018). Expertise and behaviour: Aspects of Cognitive Translation Studies [Special section]. HERMES. Journal of Language and Communication in Business, 57.

Korpal, P. (2016). Interpreting as a stressful activity: Physiological measures of stress in simultaneous interpreting. Poznań Studies in Contemporary Linguistics, 52(2), 297-316. https://doi.org/10.1515/psicl-2016-0011

Korpal, P., \& Jasielska, A. (2019). Investigating interpreters' empathy: Are emotions in simultaneous interpreting contagious? Target, 31(1), 2-24. https://doi.org/10.1075/target.17123.kor

Koskinen, K. (2020). Translation and affect. Essays on sticky affects and translational affective labour. John Benjamins. https://doi.org/10.1075/btl.152

Kruger, J. L., Soto-Sanfiel., M. T., Doherty, S., \& Ibrahim, R. (2016). Towards a cognitive audiovisual translatology: Subtitles and embodied cognition. In R. Muñoz Martín (Ed.), Reembedding translation process research (pp.171-194). John Benjamins. https://doi.org/10.1075/btl.128.09kru

Lacruz, I., \& Jääskeläinen , R. (Eds.). (2018). Innovation and expansion in translation process research. John Benjamins. https://doi.org/10.1075/ata.xviii

Latour, B. (2007). Reassembling the social: An introduction to Actor Network Theory. Oxford University Press.

Li, D., Lei, V. L. C., \& He, Y. (Eds.). (2019). Researching cognitive processes of translation. Springer. https://doi.org/10.1007/978-981-13-1984-6

Massey, G. (2019). The bigger picture: experiential learning from the classroom to the organization. In D. Kiraly \& G. Massey (Eds.) Towards authentic experiential learning in translator education (pp. 210-231). Cambridge Scholars.

Mellinger, C. D., \& Hanson, T. A. (2017). Quantitative research methods in translation and interpreting studies. Routledge. https://doi.org/10.4324/9781315647845

Moscovici, S. (1984). The phenomenon of social representations. In R. Farr \& S. Moscovici (Eds.), Social representations (pp. 3-69). Cambridge University Press.

Muñoz Martín, R. (2010). On paradigms and Cognitive Translatology. In G. M. Shreve \& E. Angelone (Eds.), Translation and cognition (pp. 169-187). John Benjamins. https://doi.org/10.1075/ata.xv.10mun

Muñoz Martín, R. (2014). A blurred snapshot of advances in translation process research. MonTI Special Issue - Minding translation 1, 49-84. https://doi.org/10.6035/MonTI.2014.ne1

Muñoz Martín, R. (Ed.). (2014). Minding translation / Con la traducción en mente [special issue] MonTI, 1.

Muñoz Martín, R. (2016a). Reembedding translation process research: An introduction. In R. Muñoz Martin (Ed.), Reembedding translation process research (pp. 1-20). John Benjamins. https://doi.org/10.1075/btl.128.01mun

Muñoz Martín, R. (2016b). Processes of what models? On the cognitive indivisibility of translation acts and events. Translation Spaces, 5(1), 145-161. https://doi.org/10.1075/ts.5.1.08mun

Muñoz Martín, R. (2017). Looking toward the future of Cognitive Translation Studies. In J. W. Schwieter \& A. Ferreira (Eds.), The handbook of translation and cognition (pp. 555-571). Wiley-Blackwell. https://doi.org/10.1002/9781119241485.ch30

Muñoz Martín, R. \& González Fernández, C. A. (in press). Cognitive Translatology: A primer, revisited. 语言、翻译与认知(Studies in Language, Translation \& Cognition).

Muñoz Martín, R., \& Halverson, S. L. (Eds.). (2020). Multilingual mediated communication and cognition. Routledge. https://doi.org/10.4324/9780429323867 
Xiao, K. \& Muñoz, R. (2020). Cognitive Translation Studies: Models and methods at the cutting edge. Linguistica Antverpiensia, New Series: Themes in Translation Studies, 19, 1-24

Muñoz Martín, R. \& Martín de León, C. (2020). Translation and cognitive science. In F. Alves \& A. L. Jakobsen. (Eds.). The Routledge handbook of translation and cognition. Routledge. https://doi.org/10.4324/9781315178127-5

Muñoz Martín, R., \& Xiao, K. (Eds.). (2020). Cognitive Translation Studies: Theoretical models and methodological criticism [Special issue]. Linguistica Antverpiensia, New Series - Themes in Translation Studies, 19.

Neubert, A. (1994). Competence in translation: A complex skill, how to study and how to teach it. In M. Snell-Hornby, F. Pöchhacker \& K. Kaindl (Eds.), Translation Studies. An interdiscipline (pp. 411-420). John Benjamins. https://doi.org/10.1075/btl.2.48neu

Nida, E. A. (1964). Toward a science of translating. Brill.

Nitzke, J. (2019). Problem solving activities in post-editing and translation from scratch. Language Science Press. https://doi.org/10.4324/9780429030376-5

O'Brien, S. (2013). The borrowers: Researching the cognitive aspects of translation. Target, 25(1), 517. https://doi.org/10.1075/target.25.1.02obr

Pinter, I. (1969). Der Einfluss der Übung und Konzentration auf simultanes Sprechen und Hören. [Unpublished doctoral dissertation]. University of Vienna.

Ramos Caro, M. (2015). The emotional experience of films: does audio description make a difference? The Translator, 21, 68-94. https://doi.org/10.1080/13556509.2014.994853

Ransdell, S., Barbier, M.-L., \& Niit, T. (2006). Metacognitions about language skill and working memory among monolingual and bilingual college students: When does multilingualism matter? International Journal of Bilingual Education and Bilingualism, 9(6),728-741. https://doi.org/10.2167/beb390.0

Risku, H. (2014). Translation process research as interaction research: From mental to socio-cognitive processes. MonTI Special Issue - Minding Translation, 331-353. https://doi.org/10.6035/MonTI.2014.ne1.11

Risku, H., Rogl, R., \& Milošević, J. (Eds.). (2017). Translation practice in the field. Current research on socio-cognitive processes. [Special issue] Translation Spaces 6 (1). https://doi.org/10.1075/ts.6.1

Rojo López, A. M., \& Ramos Caro, M. (2016). Can emotion stir translation skill? Defining the impact of positive and negative emotions on translation performance. In R. Muñoz Martín (Ed.), Reembedding translation process research (pp. 107-130). John Benjamins. https://doi.org/10.1075/btl.128.06roj

Saldanha, G., \& O'Brien, S. (2014). Research methodologies in translation studies. Routledge. https://doi.org/10.4324/9781315760100

Sandrock, U. (1982). 'Thinking-aloud Protocols' (TAPS)-Ein Instrument zur Dekomposition des complexen Prozesses 'Übersetzen'. [Unpublished master's thesis]. University of Kassel.

Schweizer, T. (1996) Muster sozialer Ordnung: Netzwerkanalyse als Fundament der Sozialethnologie. D. Reimer.

Schwieter, J. W., \& Ferreira, A. (2017). Bilingualism in cognitive translation and interpreting studies. In J. W. Schwieter \& A. Ferreira (Eds.), The handbook of translation and cognition (pp.144-164). Wiley-Blackwell. https://doi.org/10.1002/9781119241485.ch8

Seeber, K. (2011). Cognitive load in simultaneous interpreting: Existing theories-New models. Interpreting, 13 (2), 176-204. https://doi.org/10.1075/intp.13.2.02see

Seeber, K. (2013). Cognitive load in simultaneous interpreting: Measures and methods. Target, 25 (1), 18-32. https://doi.org/10.1075/target.25.1.03see

Seleskovitch, D. (1968). L'interprète dans les conférences internationales: problèmes de langage et de communication. Minard. 
Xiao, K. \& Muñoz, R. (2020). Cognitive Translation Studies: Models and methods at the cutting edge. Linguistica Antverpiensia, New Series: Themes in Translation Studies, 19, 1-24

Shreve, G. M., \& Diamond, B. J. (2016). Cognitive neurosciences and the information processing paradigm. In Y. Gambier \& L. van Doorslaer (eds.), Border crossings: Translation Studies and other disciplines (pp. 141-167). John Benjamins. https://doi.org/10.1075/btl.126.07shr

Sperber, D., \& Wilson, D. (1986). Relevance: Communication and cognition. Blackwell.

Stachowiak-Szymczak, K. (2019). Eye movements and gestures in simultaneous and consecutive interpreting. Springer. https://doi.org/10.1007/978-3-030-19443-7

Su, W. (2020). Eye-tracking processes and styles in sight translation. Springer. https://doi.org/10.1007/978-981-15-5675-3

Szarkowska, A., \& Gerber-Morón, O. (2018). Viewers can keep up with fast subtitles: Evidence from eye movements. Plos ONE, 13(6), e0199331. https://doi.org/10.1371/journal.pone.0199331

Szarkowska, A., Krejtz, K., Dutka, Ł. , \& Pilipczuk, O. (2016). Cognitive load in intralingual and interlingual respeaking: A preliminary study, Poznań Studies in Contemporary Linguistics, 52(2), 209-233. https://doi.org/10.1515/psicl-2016-0008

Teixeira, C., \& O'Brien, S. (2017). Investigating the cognitive ergonomic aspects of translation tools in a workplace setting. Translation Spaces, 6(1), 79-103. https://doi.org/10.1075/ts.6.1.05tei

Timarová, S. (2008). Working memory and simultaneous interpreting. In P. Boulogne (Ed.), Translation and its others: Selected papers of the cetra research seminar in translation studies 2007 (pp. 128). KU Leuven Centre for Translation Studies.

Toury, G. (1991). Experimentation in translation studies: Achievements, prospects and some pitfalls. In S. Tirkkonen-Condit (Ed.), Empirical research in translation and intercultural studies (pp. 45-66). Narr.

Tuominen, T., Jiménez Hurtado, C., \& Ketola, A. (2018). Why methods matter: Approaching multimodality in translation research. Linguistica Antverpiensia, New Series: Themes in Translation Studies, 17, 1-21.

Vieira, L. Nunes. (2014). Indices of cognitive effort in machine translation post-editing. Machine Translation, 28, 187-216. https://doi.org/10.1007/s10590-014-9156-x

Walker, C. (2020). An eye-tracking study of equivalent effect in translation. The reader experience of literary style. Springer.

Walker, C., \& Federici, F. M. (Eds.). (2018). Eye tracking and multidisciplinary studies on translation. John Benjamins. https://doi.org/10.1075/btl.143

Whyatt, B. (Ed.). (2016). Language processing in translation [Special issue]. Poznan Studies in Contemporary Linguistics, 52(2).

Wilss, W. (1996). Knowledge and skills in translator behaviour. John Benjamins. https://doi.org/10.1075/btl.15

Xiao, K., \& Halverson, S. L. (Eds.). (In press). Developments in Cognitive Translation and Interpreting Studies [Special issue]. Cognitive Linguistic Studies, 8(2). 